\title{
A participação brasileira na construção da Declaração Universal sobre Bioética e Direitos Humanos da UNESCO
}

\section{Brazilian participation in the construction of the Universal Declaration on Bioethics and Human Rights of UNESCO}

\author{
Swedenberger do Nascimento Barbosa \\ Assessoria Especial do Presidente da República, Brasília, \\ Distrito Federal, Brasil. \\ swedenberger.barbosa@planalto.gov.br
}

Resumo: O trabalho tem por objetivo registrar e analisar os diversos momentos da participação oficial do Brasil na construção da Declaração Universal sobre Bioética e Direitos Humanos da UNESCO: desde o período preparatório do documento inicial, proposto para discussão e nas três sessões finais de debates e homologação da mesma, realizadas em Paris, respectivamente, em abril, junho e outubro de 2005. Relata, ainda, as iniciativas promovidas pelo Governo brasileiro no sentido de divulgar, promover e implementar os princípios relacionados com a Declaração no contexto do país.

Palavras-chave: Declaração de Bioética da UNESCO. Participação brasileira. Divulgação, promoção e implementação.

\begin{abstract}
The purpose of this work is to registering and analyzing the different moments of the official Brazilian participation in the construction of Universal Declaration on Bioethics and Human Rights of UNESCO: since the period of preparation of the initial document for discussion, and the three final sections of debates and homologation of it, held in Paris, respectively in April, June and October, 2005. The work reports also the initiatives of Brazilian government in order to divulging, promoting and implementing the principles related to the Declaration in the country's context.
\end{abstract}

Key words: UNESCO's Declaration of Bioethics. Brazilian participation. Divulgation, promotion and implementation. 


\section{Revista Brasileira de Bioética}

O Brasil tem um histórico de presença constante e afirmativa em atividades internacionais relacionadas com a construção de declarações humanitárias de diferentes naturezas convocadas pela Organização das Nações Unidas (ONU), desde a histórica Declaração Universal dos Direitos Humanos, homologada em 1948, no período de re-estruturação política e ética internacional, verificado após o término da Segunda Guerra Mundial. Com relação à recente Declaração Universal sobre Bioética de Direitos Humanos - homologada unanimemente em 19 de Outubro de 2005, em Paris, por aclamação dos 191 países-

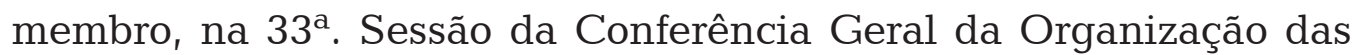
Nações Unidas para a Educação, a Ciência e a Cultura (UNESCO) - não poderia ser diferente.

Desde a emissão do primeiro documento básico (draft) produzido pelos professores Giovanni Berlinguer (Itália) e Leonardo de Castro (Filipinas), a pedido do International Bioethics Committee (IBC) da UNESCO, em 13 de junho de 2003, até a data de homologação da Declaração, o Brasil - por intermédio do Ministério das Relações Exteriores; da Representação Brasileira na UNESCO; da Casa Civil da Presidência da República, dos Ministérios da Saúde, Ciência e Tecnologia, Justiça, Meio Ambiente e Secretaria Especial de Direitos Humanos; da Sociedade Brasileira de Bioética; da Academia Brasileira de Ciências; e da Cátedra UNESCO de Bioética da Universidade de Brasília, participou ativamente em praticamente todas as etapas do processo preparando-se com toda profundidade e rigor necessários.

O presente texto tem por objetivo registrar, analisar e tornar público os diversos momentos da participação - direta e indireta - do Brasil na construção da Declaração: desde o período de intensas e polêmicas discussões que antecedeu as reuniões finais de preparação do documento que serviria de base para as reuniões formais decisivas; a fase da construção do documento propriamente dito e sua homologação; chegando ao momento imediatamente após 19 de outubro de 2005, com a Declaração já de domínio público internacional, oportunidade em que o Brasil cumpriu seu papel com relação a sua divulgação e implementação efetiva. 


\section{Participação brasileira antes das reuniões finais de Paris - 2003/2004}

Assim que a Sociedade Brasileira de Bioética (SBB) e a Cátedra UNESCO de Bioética da Universidade de Brasília (UnB), então ainda denominada de Núcleo de Estudos e Pesquisas em Bioética, tiveram notícia da primeira versão da futura Declaração produzida por Berlinguer e Castro - denominada Informe do IBC sobre a Possibilidade de Elaborar um Instrumento Universal sobre Bioética - imediatamente enviaram cópia aos associados da entidade, solicitando sugestões para encaminhamento. O IBC é um organismo que faz parte da estrutura oficial da UNESCO, sendo composto por membros independentes não indicados obrigatoriamente pelos países-membro, como foi o caso do titular de nacionalidade brasileira entre os anos 2004 e 2007, indicado alea-toriamente, sem consulta ao país, pela direção da Divisão de Ética em Ciência e Tecnologia da UNESCO, instância de segundo escalão naquele organismo. Na oportunidade, provavelmente por essa distorção, as sugestões recebidas e direcionadas pela SBB infelizmente não foram sequer encaminhadas ao referido Comitê, pelo não comparecimento do membro titular de nacionalidade brasileira às diversas reuniões oficiais, tanto as programadas naquele período quanto as demais durante todo o transcurso de seu mandato.

É indispensável registrar que a idéia inicial do Comitê da UNESCO era construir um conjunto de "instrumentos universais de bioética", de caráter predominantemente normativo. Porém, com a introdução de mudanças unilaterais e profundas, voltadas ao interesse exclusivo dos países ricos, o IBC, infelizmente, praticamente descaracterizou as idéias originais dos dois relatores, já no primeiro momento de divulgação desse texto inicial. Portanto, desde o início da construção da Declaração, as posições brasileiras começaram a divergir da proposta que, basicamente, o IBC estava procurando elaborar e encaminhar.

Esse primeiro documento enviado pela SBB e pela Cátedra UNESCO de Bioética da UnB ao IBC, consolidava críticas ao rascunho original, em perfeita consonância com a posição formal do Brasil, elaborada pelo Ministério das Relações Exteriores, com o apoio de vários Ministérios e entidades da sociedade civil. Entre outras, foram formuladas as seguintes questões: 


\section{Revista Brasileira de Bioética}

- A palavra "normas" não deve fazer parte do texto, muito menos do título. A bioética, pluralista e laica, dirigida às sociedades sabidamente secularizadas do Século XXI, neste caso representada por um organismo internacional como a UNESCO, não deve ser basicamente normativa.

- A palavra "sagrado" aparece na primeira página do documento. Surge aí um problema de inteligibilidade quando se quer, ao mesmo tempo, respeitar as liberdades fundamentais e se impor um "dever" sagrado, portanto absoluto, o que leva a um impasse lógico e prático. A proposta é que se substitua o termo em questão por outro menos polêmico, adaptado a um mundo em que devem conviver religiosos e laicos, defensores de deveres absolutos, defensores de deveres substantivos e defensores de direitos relativos e contextualizados.

- O documento não menciona a questão ambiental. É impossível se pensar em uma "ética da vida humana" sem levar em consideração a imensa biodiversidade terrestre e a necessidade de respeito e controle dos habitats naturais, incluindo em alguns casos espécies animais e vegetais.

- O documento original interpreta a raiz "bio" de bioética estritamente como do campo da Biologia e não da Vida, que tem um sentido bem mais amplo. A Declaração deve dar esse último sentido à bioética, fugindo da visão reducionista estadunidense de uma bioética exclusivamente biomédica. Em um mundo com crescentes índices de exclusão social onde os sujeitos/pessoas não são de modo algum "iguais" e muito menos "autônomos", um texto internacional de bioética não pode se omitir diante dessas questões.

- Alguns temas de inegável transcendência para a bioética, como o acesso e a alocação de recursos escassos em saúde, importantes para as nações pobres do mundo, estão substituídos pela ambígua e frágil expressão healthcare. O tema do acesso à saúde pública deve estar claramente explicitado no documento como um direito de cidadania.

Entre esse momento inicial e durante o ano 2004, nada menos que cinco diferentes versões da Declaração foram sendo sequencialmente 
divulgadas pelo IBC. A construção mostrava-se difícil e o consenso parecia cada dia mais distante, sobrepujado pelos desejos dos países ricos do Hemisfério Norte, que queriam um documento enxuto, exclusivamente biomédico e biotecnológico, e as nações pobres e em desenvolvimento do Hemisfério Sul, que almejavam incluir na agenda também as questões sociais, sanitárias e ambientais. Diante disso, um grupo de qualificados bioeticistas ligados à Rede Latino-Americana e do Caribe de Bioética da UNESCO - REDBIOÉTICA, atendendo a um convite do Ministério da Justiça e Direitos Humanos da Argentina, promoveu uma estratégica reunião em Buenos Aires, na primeira semana de novembro de 2004. Esta reunião contou com a presença da então presidente do IBC, pesquisadora canadense Michèle Jean, dos membros titulares do IBC, Christian Bik (França) e Hector Gross Espiell (Uruguai) e do senhor Henk ten Have, diretor da Divisão de Ética em Ciência e Tecnologia da UNESCO.

A reunião foi de elevada qualidade e duríssima nas argumentações que defendiam as posições preconizadas pelos países da Região. No final do encontro, dois documentos foram divulgados. Um primeiro texto mais formal, dirigido oficialmente ao IBC, propunha que as modificações aqui já mencionadas fossem incluídas na pré-Declaração decisiva que seria discutida em Paris em janeiro 2005 pelo IBC, IGBC (Inter-Governmental Bioethics Committe), e demais convidados. O segundo documento, firmado por pesquisadores de 11 países da América Latina e Caribe (Argentina, Bolívia, Brasil, Colômbia, Chile, Cuba, México, Paraguai, República Dominicana, Uruguai e Venezuela), tinha forte tom político, tendo sido denominado de Carta de Buenos Aires sobre Bioética y Derechos Humanos, traduzida para o português e inglês e distribuída por todo o mundo. Essa carta foi devastadora para as pretensões reducionistas na Declaração e teve um papel central nas mudanças daí em diante alcançadas.

Entre outros pontos, a carta de Buenos Aires ${ }^{1}$ defendia:

- Que as conquistas representadas pelo Código de Nüremberg e pela Declaração de Helsinque, além de outros instrumentos

1 Publicada na íntegra pela Revista Brasileira de Bioética 2005, Volume 1, número 3, pp. 317-322. 


\section{Revista Brasileira de Bioética}

éticos internacionais, fossem mantidas em sua essência.

- Que a Declaração contivesse os valores fundamentais recolhidos dos documentos mundiais e do Sistema Interamericano de Direitos Humanos, como o valor da vida, a dignidade, a identidade, a igualdade, a integridade, a liberdade, a justiça e o bem estar de indivíduos, famílias e comunidades.

- Que a bioética, além dos cuidados com os temas relacionados ao desenvolvimento científico e tecnológico, deveria passar a se ocupar, também, das condições que proporcionam um meio ambiente ecologicamente equilibrado na biodiversidade natural.

- Que fossem incluídos também no texto, de forma explícita, os problemas éticos relacionados ao direito e à atenção aos cuidados com a vida e a saúde, sendo por isso um pressuposto básico a incorporação, na Declaração, do conceito de saúde integral, entendida nas suas perspectivas biológica, psicológica, social e ambiental.

- Que o desenvolvimento das capacidades humanas essenciais só é possível quando as necessidades básicas são satisfeitas. Em razão disso, todos os seres humanos devem ter acesso a água potável, alimentação, moradia, atenção médica e a serviços públicos de saúde; sem cujas garantias não é possível considerar nenhuma sociedade como justa.

- Que uma verdadeira e democrática declaração universal sobre bioética deve rechaçar todas as formas de discriminação, xenofobia ou racismo, assim como a guerra e outras formas de agressão ou de práticas aberrantes que favorecem uma cultura de morte e opressão, incompatíveis com a paz mundial e com as liberdades fundamentais.

Os estrangeiros convidados para a reunião de Buenos Aires saíram bastante impressionados com a força dos argumentos e com a competência técnica com que foram apresentados, comprometendose a levar ao IBC as propostas formuladas pela reunião de Buenos Aires. Os bioeticistas brasileiros presentes e atuantes na oportunidade foram os professores Volnei Garrafa (UnB), Fermin Roland Schramm (Fundação Oswaldo Cruz) e José Eduardo de Siqueira (Universidade Estadual de Londrina). 
É indispensável registrar que durante o ano 2004, o governo brasileiro, por meio do Itamaraty, convocou várias reuniões para discutir a formulação das propostas que seriam levadas a partir de abril de 2005 para as reuniões finais, em Paris, de definição da Declaração. Diversos Ministérios, como o da Saúde, Meio Ambiente, Ciência e Tecnologia, Justiça e Casa Civil da Presidência da República, além de entidades, como a Sociedade Brasileira de Bioética e a Academia Brasileira de Ciências, foram partícipes ativas nessas reuniões de trabalho.

\section{Participação brasileira durante as reuniões decisivas de Paris - 2005}

O final de 2004 e início de 2005 foi um período de intensas discussões com relação à preparação do documento que iria servir de base para os debates decisivos com sobre a Declaração. Em janeiro de 2005 a UNESCO reuniu o IBC e o IGBC, este último composto por membros oficialmente designados pelos países-membro, juntamente com alguns especialistas e consultores, em Paris, para definir o rascunho (draft ou borrador) final que deveria ser apresentado à na I Reunião dos Peritos Governamentais Nível II, marcada para 8 a 10 de abril.

Nestes encontros ficaram marcadas as gritantes diferenças entre o que desejavam os países ricos e as posições das nações em desenvolvimento. Enquanto os primeiros, liderados pelos Estados Unidos (EUA) e secundados pela Alemanha e Reino Unido, persistiam na proposta de um documento neutro, "asséptico" e direcionado quase que exclusivamente às temáticas biomédicas e biotecnológicas, as nações do Hemisfério Sul do mundo tentavam demonstrar a necessidade de incluir definitivamente na agenda bioética do Século XXI também a temática dos direitos humanos, além das questões sociais, sanitárias e ambientais.

As dificuldades começaram no Artigo 1, que deveria trazer a definição de bioética. Enquanto os países do Norte queriam uma definição pautada no universalismo ético, as nações do Sul defenderam firmemente o relativismo ético e o respeito ao pluralismo moral e cultural. A única conclusão palpável destes três primeiros dias de discussão foi de que a Declaração não traria a definição de bioética, ficando essa tarefa ao encargo de cada país, região geográfica ou cultura. Vitória inicial do Sul. 


\section{Revista Brasileira de Bioética}

Se a discussão não avançou tanto quanto os países periféricos desejavam, o resultado final deste primeiro round deixou as nações centrais bastante irritadas. Em um momento tenso dos debates, o Embaixador brasileiro na UNESCO na época, Antonio Augusto Dayrrel de Lima, chegou a exigir que não fossem mais permitidas intervenções ao Consultor de Bioética da Organização Mundial da Saúde (OMS), Alexander Capron - conhecido nos meios internacionais da bioética como porta-voz do indefensável double standard para as pesquisas com seres humanos - por este estar extrapolando seu papel de consultor de um organismo das Nações Unidas, em defesa apaixonada das teses estadunidenses, seu país de origem.

Sob o ponto de vista da participação política nessa I Reunião, os países da América Latina, chegaram à Paris altamente mobilizados. Graças ao papel organizativo da REDBIOÉTICA, era significativo número de delegados, assessores e técnicos de apoio às delegações dos Estados. Partícipes ativos nas atividades da REDE ou tendo algum vínculo com ela, facilitaram o diálogo e o encaminhamento de propostas. Com o fracasso dos avanços registrado na primeira reunião, foi nomeada uma Comissão formada por alguns países e coordenada pelo Embaixador do Uruguai, com a missão de organizar uma nova versão - mais flexível - de rascunho da Declaração, a qual seria discutida na reunião de junho, com o compromisso prévio de uma maior tolerância nos debates entre as diferentes posições.

O encontro chave para a construção da versão final da Declaração aconteceu no II Encontro dos Peritos Governamentais Nível II, realizada entre os dias 20 e 24 de junho. Durante toda semana, da manhã à noite, diplomatas, delegados e assessores digladiaram-se em Paris em defesa de suas posições. O tema mais delicado foi o do Artigo 14, relacionado à Responsabilidade social e saúde. Pelo fato do acesso à saúde não ser reconhecido na Constituição estadunidense como um direito universal do cidadão, os delegados dos EUA solicitaram suspensão da reunião naquele dia para consultar Washington. Prevaleceu o bom-senso da maioria e o artigo acabou aprovado, depois de incontáveis idas e vindas.

Nesta II Reunião, o papel dos membros da REDBIOÉTICA ficou ainda mais visível e importante. Muitos membros de seus quadros atuaram decisivamente na aproximação das propostas latino-ameri- 
canas e caribenhas, além de ampliá-las aos países africanos (com os quais, na sua grande maioria, o Brasil sempre teve uma histórica proximidade) e alguns países asiáticos, principalmente a Índia. Não se pode deixar de mencionar o papel relevante e de alta qualidade desenvolvido na oportunidade e em toda essa difícil travessia, dos delegados do Brasil e Argentina, professores Volnei Garrafa e Juan Carlos Tealdi, respectivamente. Com relação ainda à delegação brasileira que participou das reuniões, é indispensável mencionar, além da extraordinária atuação do Embaixador Dayrell, já mencionado, a competente presença do Ministro Luiz Alberto Figueiredo Machado, com intervenções sempre muito respeitadas, além do incansável Secretário Álvaro Vereda, todos diplomatas do Ministério das Relações Exteriores, na época servindo na delegação brasileira junto à UNESCO. A reunião decisiva de junho terminou apenas na madrugada do dia seguinte, sábado 25, sendo avaliada, dentro de todas as circunstâncias adversas e dificuldades que cercavam a construção da Declaração, como uma honrosa vitória para os países e povos do Hemisfério Sul.

Finalmente, o momento final e decisivo aconteceu, sempre em Paris, por ocasião da $33^{a}$. Sessão da Conferência Geral da UNESCO, oportunidade compartida pelos Ministros de Estado de Educação, Cultura e Ciência \& Tecnologia de todos os países-membro daquele organismo internacional das Nações Unidas, além dos delegados, assessores e técnicos já mencionados. Em memorável Assembléia cercada de enorme expectativa, no dia 19 de outubro de 2005, finalmente, foi homologada por unanimidade dos 191 países presentes, por aclamação, a versão final e definitiva da Declaração Universal sobre Bioética e Direitos Humanos, arduamente construída e tão duramente conquistada.

\section{O Brasil na divulgação, promoção e implementação da Declaração $-2006$}

A implementação da Declaração Universal sobre Bioética e Direitos Humanos, no Brasil, teve como primeiro momento importante sua apresentação aos diferentes Poderes (Executivo, Legislativo e Judiciário), instituições e à sociedade, em evento realizado em 26 de maio de 2006, no Palácio do Itamaraty, sede do Ministério das Relações Exteriores do Governo Brasileiro, com presença de mais de 400 


\section{Revista Brasileira de Bioética}

pessoas. Além do Ministério anfitrião e de vários outros Ministérios (Saúde, Ciência e Tecnologia, Meio Ambiente, Justiça...), esse evento teve o apoio decisivo da Secretaria Nacional dos Direitos Humanos, da Cátedra UNESCO de Bioética da Universidade de Brasília e da Representação da UNESCO no Brasil. Como frisado, para se chegar até aquele momento, foi decisiva a participação da representação brasileira na 33 ${ }^{a}$ Conferência Geral da Unesco, realizada em Paris, quando aprovada a Declaração, assim como nos fóruns que a antecederam.

Posteriormente, em atividades que contaram com o apoio da Cátedra UNESCO de Bioética da UnB e da Coordenação Regional de Ciências Sociais e Humanas da UNESCO, com sede no México, foram organizadas reuniões que objetivaram maior divulgação e implementação da Declaração em São Paulo (na Faculdade de Saúde Pública da Universidade de São Paulo - abril/2006) e Curitiba (Conselho Regional de Medicina do Paraná - agosto/2006). Além disso, é indispensável registrar a iniciativa do Governo da Argentina por meio do seu Ministério da Justiça e Direitos Humanos, com o apoio de diversos países da região, inclusive da Presidência da República do Brasil, em promover, em outubro de 2006, em Buenos Aires, o Foro Regional de América Latina para la Aplicación de la Declaración Universal sobre Bioética y Derechos Humanos. Todas estas iniciativas, portanto, demonstram o interesse, preocupação e compromisso dos países da América Latina, e especialmente o Brasil, em tornar a Declaração uma letra viva no seu contexto legislativo e administrativo.

O Brasil é um país democrático, republicano e laico. Possui uma Constituição na qual está prevista a garantia aos direitos individuais e coletivos assim como a proteção social. Assim, sua lei maior indica forte compromisso com a população. A transformação desse compromisso formal em política pública, em programas e ações de governo voltados ao interesse coletivo de maneira ampla, é a uma das grandes preocupações do Presidente da República, Luiz Inácio Lula da Silva. Dessa forma, a pauta da Bioética e Direitos Humanos ganha força no atual governo ao reconhecer, como citado na Declaração, que “... decisões sobre questões éticas na medicina, nas ciências da vida e nas tecnologias associadas podem ter impacto sobre indivíduos, famílias, grupos ou comunidades e sobre a humanidade como um todo" (1).

Para implementar a Declaração no Brasil, é importante destacar 
pelo menos duas questões fundamentais previstas na mesma: 1) Recusa a atos contrários aos Direitos Humanos, às liberdades fundamentais e à dignidade humana; 2) O papel dos Estados na promoção da Declaração, especialmente o previsto em seu Artigo 22 letra a, reproduzido abaixo:

"Os Estados devem tomar todas as medidas adequadas de caráter legislativo, administrativo ou de qualquer outra natureza, de modo a implementar os princípios estabelecidos na presente Declaração e em conformidade com o direito internacional e com os direitos humanos. Tais medidas devem ser apoiadas por ações nas esferas da educação, formação e informação ao público" (2).

A partir dessas considerações e para ilustrar o texto, é necessário mencionar algumas medidas legislativas e administrativas que estão ora em curso no Brasil e que, para efeito didático, são relacionadas como: medidas Legislativas; medidas de Governo; envolvimento da sociedade civil; e Poder Judiciário.

\section{Medidas Legislativas}

Pode-se afirmar que a mais importante delas e que se relaciona diretamente com os princípios da Declaração é o Projeto de Lei (PL) número 6032/2005, enviado ao Congresso Nacional pelo governo brasileiro, criando o Conselho Nacional de Bioética, como órgão de assessoramento do Presidente da República. A proposta define entre as competências deste Conselho:

"Emitir pareceres sobre implicações morais e éticas das questões emergentes ou persistentes que tenham ou possam vir a ter impacto na vida humana, na qualidade de vida, no meio ambiente e na pluralidade étnica, religiosa e cultural" (3).

Há que se registrar que embora as recomendações da Declaração sejam consideradas formalmente como "normas não vinculantes" no sentido jurídico estrito, a Constituição Federal em seu Art. $5 \S 1^{\circ} \mathrm{e}$ $2^{\circ}$ define que "as normas definidoras de direitos e garantias funda- 


\section{Revista Brasileira de Bioética}

mentais têm aplicação imediata" e "os direitos e garantias expressos nesta Constituição não excluem outros decorrentes do regime e dos princípios por ela adotados, ou dos tratados internacionais em que a República Federativa do Brasil seja parte" o que implica na internalização dessas recomentações (4). Também,especialistas em Direito Internacional, como o reconhecido jurista e diplomata uruguaio Hector Gross Espiell, a reconhecem como de valor referencial legal para a temática dos direitos humanos universais. De todo modo, pelo rumo que indicam, trata-se de um documento de significativa importância para as futuras legislações específicas a serem construídas no Congresso Nacional brasileiro.

\section{Medidas de Governo}

Estas iniciam e se realizam no âmbito do Poder Executivo Federal. Neste sentido, pode-se citar a discussão ora em curso no país de criar um Comitê de Acompanhamento Governamental para Implementação da Declaração Universal sobre Bioética e Direitos Humanos. Alguns passos nessa direção já foram dados, a partir de reuniões interministeriais, coordenadas pela Presidência da República. Para dar agilidade a esse propósito, está sendo levantado todo o arcabouço legal nas diferentes áreas de governo, comparando-se com os princípios previstos na Declaração.

Associado a isso estão sendo analisadas também as políticas públicas atualmente em curso com o propósito de averiguar sua relação com a Declaração. Igualmente importante será a ampliação da relação entre os diversos órgãos de governo e os Comitês de Ética em Pesquisa Envolvendo Seres Humanos existentes no país. Registre-se nesse esforço de governo, como atual e pertinente, a revisão em curso das atribuições da Comissão Nacional de Ética em Pesquisa (CONEP), vinculada ao Conselho Nacional de Saúde, do Ministério da Saúde.

\section{Envolvimento da sociedade civil}

Para que a Declaração tenha maior legitimidade do que aquela conferida pelos poderes públicos, torna-se fundamental o envolvimento da sociedade civil no processo de sua divulgação, promoção e implementação. Para isso é necessário e urgente incorporar à discussão as diferentes representações dos trabalhadores, o setor empresarial, orga- 
nizações não governamentais (ONG), formadores de opinião, o mundo acadêmico, profissionais das áreas que se relacionam diretamente às decisões bioéticas, bem como demais profissionais das áreas de saúde, educação, comunicação, ciência e tecnologia, pesquisa, meio ambiente e direitos humanos, entre outros.

\section{Envolvimento do Poder Judiciário}

Os princípios emanados da Declaração também devem ser paulatinamente considerados e incorporados à prática quando das análises jurídicas e decisões judiciais. O envolvimento do Poder Judiciário na questão é outro esforço a ser realizado no Brasil; afinal, há forte convergência entre os princípios contidos na Declaração e o Estado Democrático de Direito que está sendo aprimorado e aprofundado no país. Para exemplificar essa relação, note-se o que consta da Declaração em seu Artigo 1: "A Declaração trata das questões éticas relacionadas à medicina, às ciências da vida e às tecnologias associadas quando aplicadas aos seres humanos, levando em conta suas dimensões sociais, legais e ambientais" (1).

\section{Breve comentário final}

É indispensável registrar uma última reflexão, renovando e reforçando a esperança de que os objetivos da Declaração Universal sobre Bioética e Direitos Humanos sejam alcançados no Brasil e em toda a América Latina, por meio de uma cooperação respeitosa entre os países da região, de forma solidária e compartilhada, garantindo, em sua totalidade, a dignidade humana e os direitos humanos.

O Brasil, como país e como nação, tem segurança de haver contribuído concretamente com a responsabilidade que lhe cabia no sentido da construção de uma Declaração politizada, coerente com os problemas sociais, sanitários e ambientais crescentemente constatados no mundo atual, principalmente nos países pobres do Hemisfério Sul. O conteúdo desse Documento, sem sombra de dúvida, consolida um avanço concreto para um novo referencial epistemológico e uma nova agenda temática para a bioética de Século XXI: uma bioética mais humana, mais palpável e mais próxima dos verdadeiros conflitos persistentes que assolam a maioria dos países periféricos da Terra. 


\section{Revista Brasileira de Bioética}

Neste sentido, para o futuro, maior ainda é a responsabilidade e compromisso do País no sentido de que essa Declaração, tão arduamente conquistada após incontáveis reuniões desenvolvidas em todo mundo e, finalmente, nos auditórios parisienses da UNESCO, se torne realidade. Tão ou mais importante que a construção e conquista de uma Declaração que ampliou substantivamente a politizou irreversivelmente a agenda bioética do Século XXI, é lograr que os preceitos nela contidos se tornem realidade concreta no cotidiano dos serviços de saúde, no respeito ao equilíbrio ambiental, nas leis e na sua aplicação efetiva, beneficiando cidadãs e cidadãos que realmente mais precisam dela.

Texto produzido a partir das conferências proferidas pelo autor, respectivamente, no "Seminário Nacional - Declaração Universal sobre Bioética e Direitos Humanos" (Brasília, Ministério das Relações Exteriores / UNESCO / Sociedade Brasileira de Bioética / Cátedra UNESCO de Bioética da UnB - 25/05/2006) e no "Foro Regional de América Latina para la Aplicación de la Declaración Universal sobre Bioética y Derechos Humanos" (Buenos Aires, Ministério de Justicia y Derechos Humanos de la República Argentina / Red Latino-Americana y del Caribe de Bioética / UNESCO - 19/10/2006).

\section{Referências}

1. UNESCO. Declaração Universal sobre Bioética e Direitos Humanos. Preâmbulo, 2005. Em: www.bioetica.catedraunesco.unb.br. Acesso em: 12/12/2006. 2. . Op.cit. Artigo 22a.

3. Brasil. Imprensa Nacional. Projeto de Lei, 6032/2005. Diário Oficial da União. Seção 1, número 194, 7/10/2005, p. 2.

4. Brasil. Constituição. República Federativa do Brasil. Brasília: Senado Federal, 1988.

Recebido: 04/12/2006 Aprovado: 28/12/2007 